\title{
Levator sling for Marcus Gunn ptosis
}

\author{
S M BETHARIA AND SUSHIL KUMAR \\ From the Dr Rajendra Prasad Centre for Ophthalmic Sciences, All India Institute for Medical Sciences, Ansari \\ Nagar, New Delhi-110029, India.
}

SUMmARY A modified simple technique of sling operation is presented in 15 cases using the levator aponeurosis as the material for the sling as originally devised by Lemagne and Bemcher. The levator is cut behind the superior transverse ligament and the posterior part of the levator is cauterised and allowed to retract into the orbit. The horns are cut from behind forwards, and the levator, which is kept attached on the tarsal plate, is used to lift up the lid. This method eliminates the jaw winking phenomenon as well as lifting the lid.

Blepharoptosis with Marcus Gunn phenomenon presents a special surgical problem ${ }^{1}$ for which there has so far been no clear-cut solution. Various surgical approaches suggested have included simple levator resection, ${ }^{2}$ Fasanella Servat operation, ${ }^{3}$ total superior rectus transplantation, ${ }^{4}$ and the use of a bilateral sling ${ }^{56}$ after tenotomy and excision of levator. Lemagne and colleagues suggested frontalis suspension with the transposed levator palpebrae superioris and also presented some experimental models and human applications of this technique. ${ }^{78}$ Neuhaus ${ }^{9}$ described a case report with a similar procedure. The purpose of this paper is to describe the levator sling in a large series of cases of Marcus Gunn ptosis.

\section{Material and methods}

Fifteen cases of blepharoptosis with the jaw winking phenomenon were operated upon by this modified technique. The preoperative examination consisted of the assessment of the amount of ptosis, levator action, Bell's phenomenon, corneal sensations, and severity of jaw winking, together with taking of clinical photographs.

Jaw winking was assessed by determining the difference between the position of the upper lid margin in primary gaze and after movement of the jaw. Jaw winking was regarded as mild to moderate when the excursion of the lid margin on moving the jaw was up to the limbus. In more severe cases the scleral rim was shown. Levator action ranged from 4 to $8 \mathrm{~mm}$ (Table 1). Bell's phenomenon and corneal sensation were good in all cases.

Correspondence to SM Betharia, MD.
SURGICAL STEPS

The operation was carried out under general anaesthesia. The lid fold was marked at its proposed site by gentian violet. A skin and orbicularis deep incision was made. The upper skin muscle flap was further dissected upwards to expose the orbital septum, which was incised to release the pad of fat (Fig. 1). The fat was retracted and the levator was carefully dissected to determine the position of the superior transverse ligament (Fig. 2). Three white cotton thread stay sutures were passed through the aponeurosis distal to the superior transverse ligament and three proximal to it. The muscle was then divided just proximal to the superior transverse ligament (Fig. 3 and 4, showing the line of division of the levator muscle and its cut edges).

The medial and lateral horns were cut from behind forwards (Figs. 5, 6) so that the levator was made free at the level of superior transverse ligament and remained attached at the tarsal plate (Fig. 7). The posterior part of the levator was cauterised and allowed to retract totally in the orbit. The levator tendon with its attachment on the tarsal plate was used as the material of the sling for brow suspension.

The frontalis sling operation of Betharia ${ }^{10}$ was used with some modifications. The muscle was tied with 5-0 merselene suture and the two arms of the suture were brought out through the single brow incision

Table 1 Symptoms

\begin{tabular}{lllll}
\hline $\begin{array}{l}\text { Total } \\
\text { cases }\end{array}$ & $\begin{array}{l}\text { Mild to } \\
\text { moderate } \\
\text { jawwinking }\end{array}$ & $\begin{array}{l}\text { Severe } \\
\text { jaw } \\
\text { winking }\end{array}$ & $\begin{array}{l}\text { Amount of } \\
\text { ptosis } \\
(\mathrm{mm})\end{array}$ & $\begin{array}{l}\text { Levator } \\
\text { action } \\
(\mathrm{mm})\end{array}$ \\
\hline 15 & 6 & 9 & $3-5$ & $4-8$ \\
\hline
\end{tabular}


Fig. 1 Showing the levator aponeurosis and the herniation of the orbital pad of fat.

Fig. 2 Arrow depicts the position of superior transverse ligament.

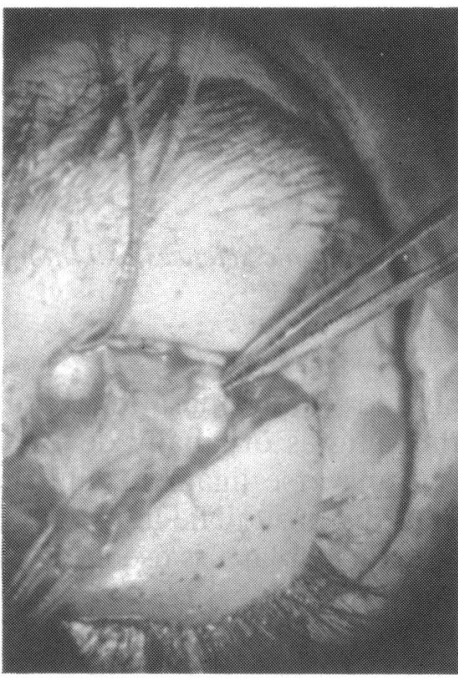

Fig. 1

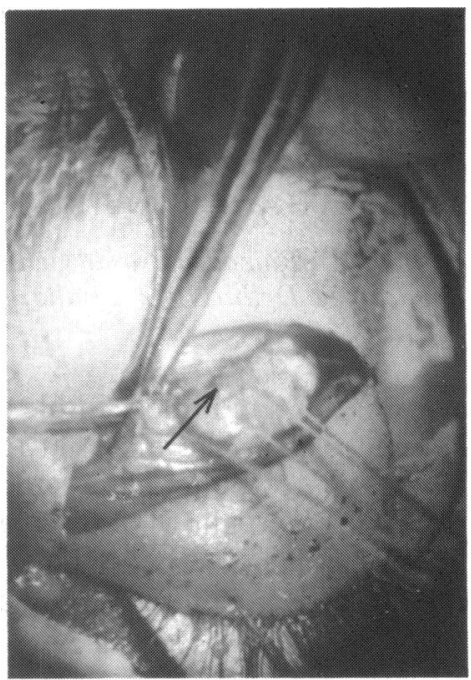

Fig. 2

with the help of a Wright fascial needle (Fig. 8). Before pulling the levator tied with the merselene suture the lid fold was formed with interrupted 5/0 black silk suture (Fig. 9). Three knots were tied and the suture was buried. The skin incision was closed with $5 / 0$ black silk suture (Fig. 10). Finally an inverted Frost suture was inserted (Fig. 11).

\section{Results}

The details of the results are given in Table 2. The postoperative follow-up of these cases ranged from six months to 15 months, average nine months.

\section{Discussion}

The two problems the surgeon faces in the correction of ptosis with the jaw winking phenomenon are the adequate correction of ptosis together with abolition

Table 2 Results

\begin{tabular}{lllll}
\hline $\begin{array}{l}\text { Good } \\
\text { correction }\end{array}$ & $\begin{array}{l}\text { Under } \\
\text { correction }\end{array}$ & $\begin{array}{l}\text { Lagophthalmos } \\
\text { (average) } \\
(\mathrm{mm})\end{array}$ & $\begin{array}{l}\text { Disappearance } \\
\text { of jaw winking }\end{array}$ & $\begin{array}{l}\text { Lidfold } \\
\text { formation }\end{array}$ \\
\hline 10 & 5 & 2 & In all cases & Good \\
\hline
\end{tabular}

Fig. 3 Dark line indicates superior transverse ligament and dotted line represents line of incision.

Fig. 4 Arrows show cut edges of the levator.

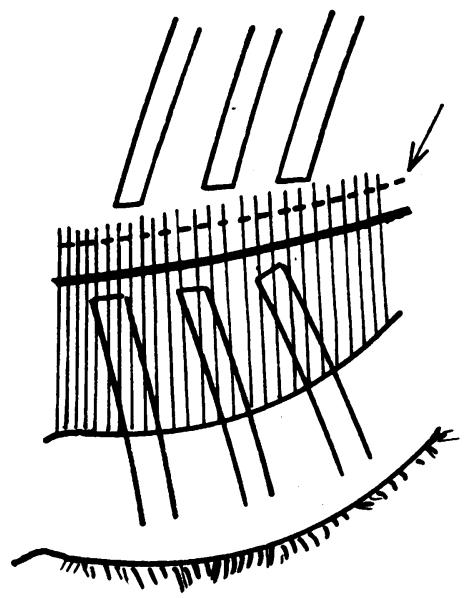

Fig. 3

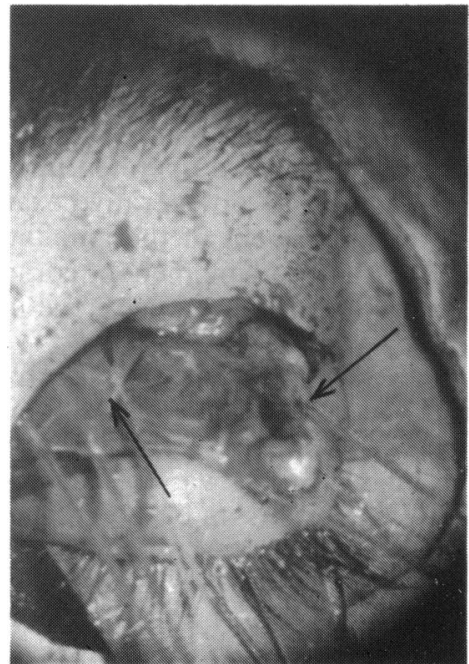

Fig. 4 


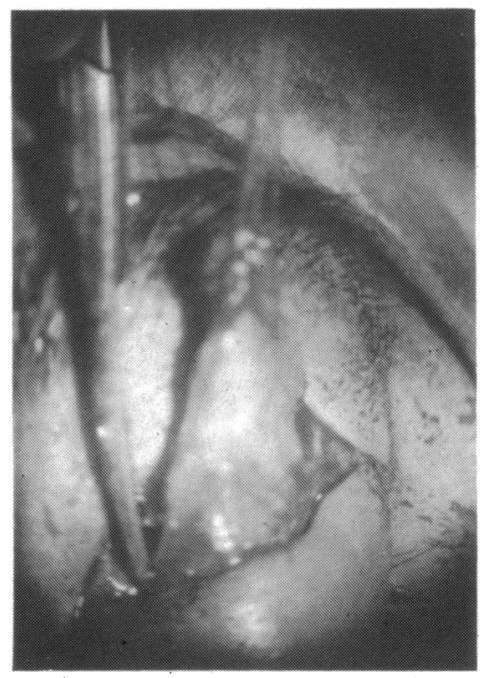

Fig. 5 Cutting of medial horn of the levator.

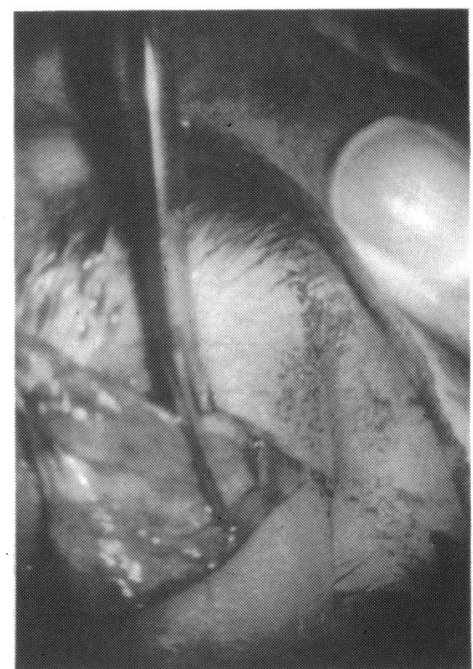

Fig. 6 Cutting of lateral horn of the levator.

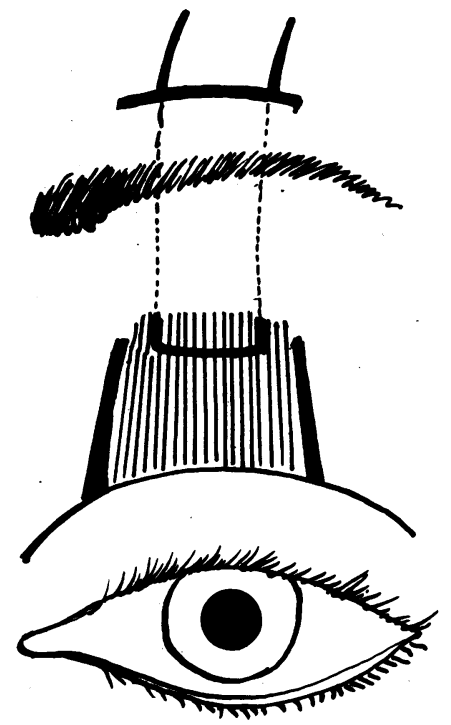

Fig. 8
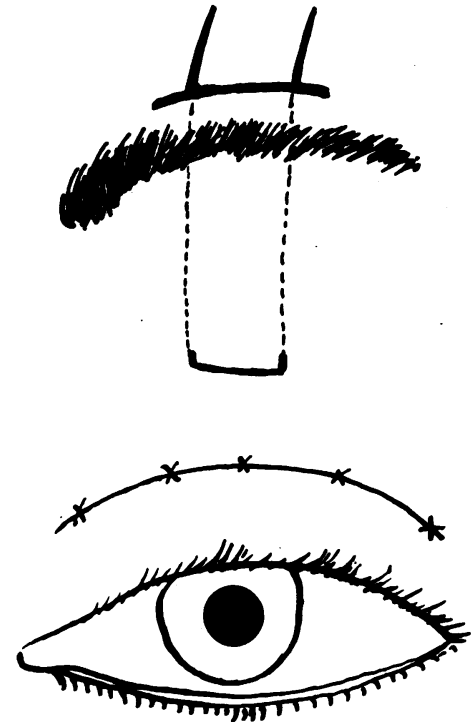

Fig. 9

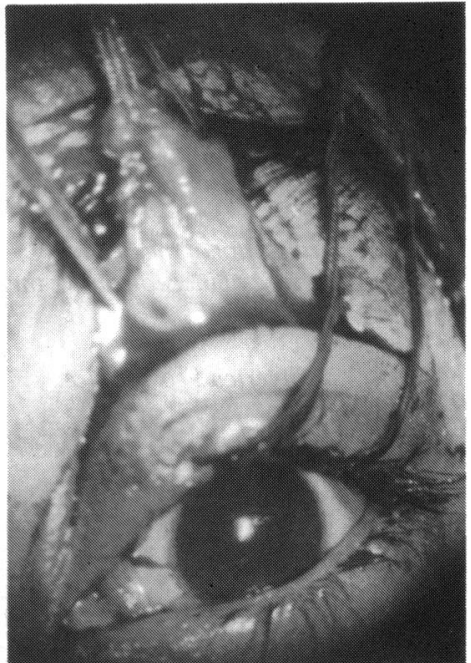

Fig. 7 Levator aponeurosis with intact attachment at the tarsal plate which was subsequently used as sling.

Fig. 8 The levator aponeurosis with merselene suture being pulled up and brought out through the single brow incision.

Fig. 9 Closure of skin incision at lid fold site.

of the abnormal innervation causing the jaw winking. This latter should be effected by the division of the levator and its entire attachment to the lid. The unique feature of the present technique is the cutting of the muscle at the level of the superior transverse ligament. The other important features of this technique are the fact that the attachment of the levator was kept intact on the tarsal plate and the levator aponeurosis was used as the sling, thereby giving an even lift of the lid without any notching. The 5-0 merselene suture was very well tolerated and has not produced suture granuloma or infection so far.

We have noticed undercorrection in five cases. This finding has also been noted earlier by Beard, ${ }^{5}$ the probable reason being the blepharospasm in the early postoperative period as the patient is accustomed to a ptotic lid and is not willing to accept an open eye. It might be minimised by patching the opposite normal eye of the patient as suggested by Illif." 
Fig. 10 Buried knot of merselene suture and closure of incision above the brow.

Fig. 11 The inverted Frost suture.

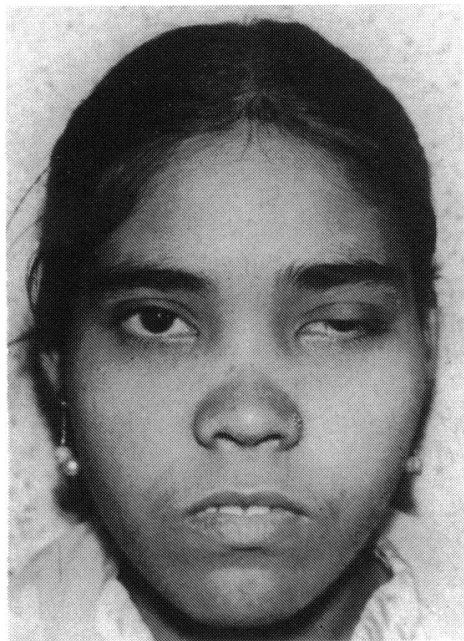

Fig. 12 Preoperative photograph showing ptosis in left eye.
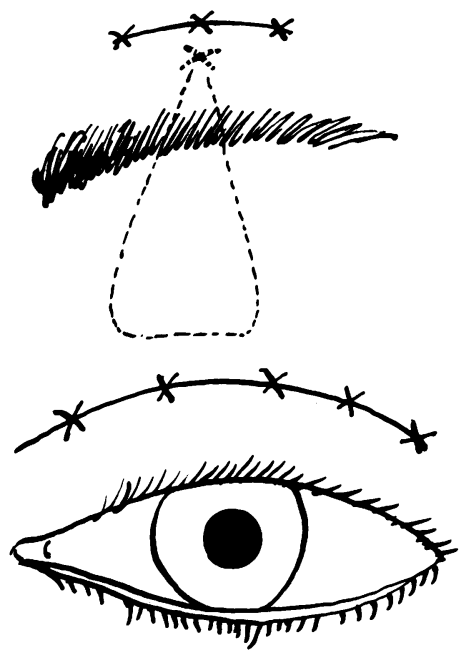

Fig. 10

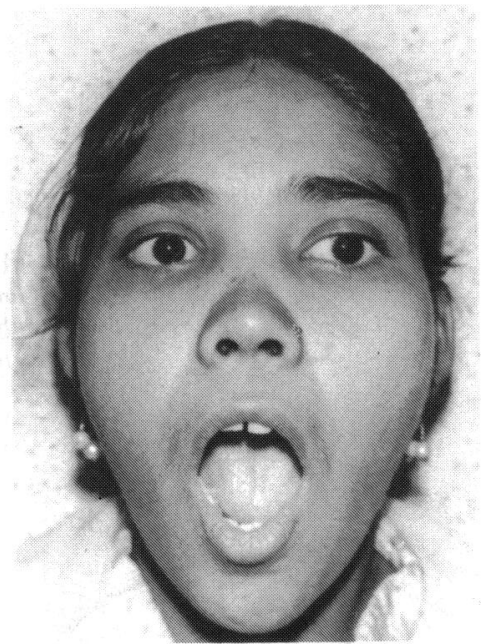

Fig. 13 Preoperative photograph showing Marcus Gunn phenomenon.

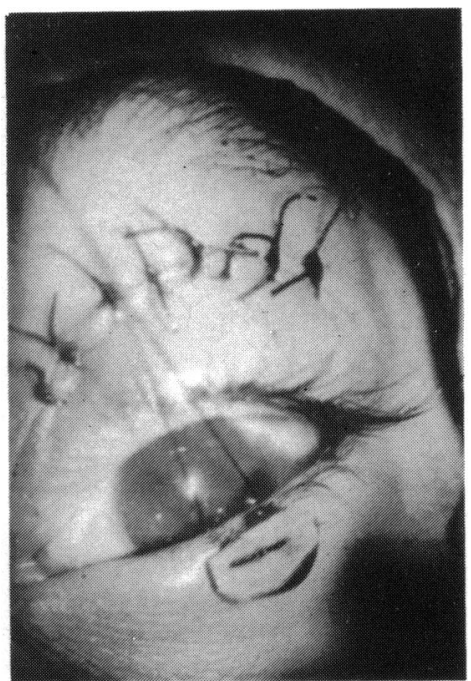

Fig. 11

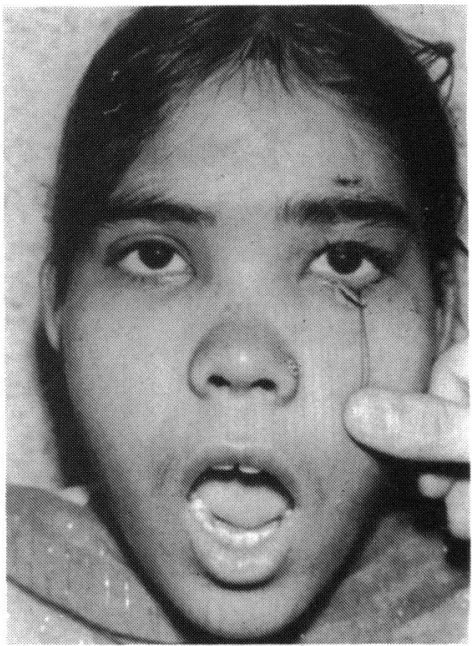

Fig. 14 Earlypostoperative photograph showing good symmetry of lids and absence of Marcus Gunn phenomenon.
We consider that slight overcorrection should be planned in all cases so that the final correction becomes cosmetically acceptable. The sling should be made taut so as to have the lid margin in a position of mild ectropion, and it should be kept at the level of the upper limbus. Lid lag which was marked in the beginning became less after a period of three months. Lagophthalmos was minimal in all cases.

This simple method of levator sling has given good results (Figs. 12 to 16 ) and has various advantages- namely, total abolition of the Marcus Gunn phenomenon, maintenance of a good contour of the lid margin, and a single stage operation obviating the use of bilateral slings with fascia lata or synthetic material.

\section{References}

1 Spaeth EB. The Marcus Gunn phenomenon. Am J Ophthalmol 1947; 30: 143-57.

2 Beard C. Ptosis. 2nd ed. St Louis; Mosby, 1969: 44-7. 


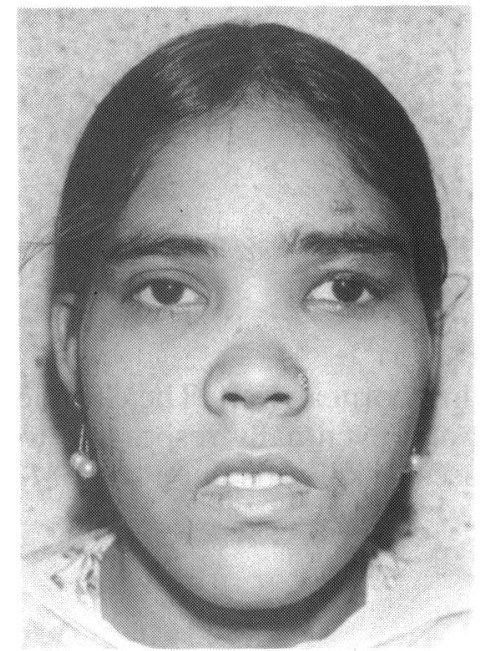

Fig. 15

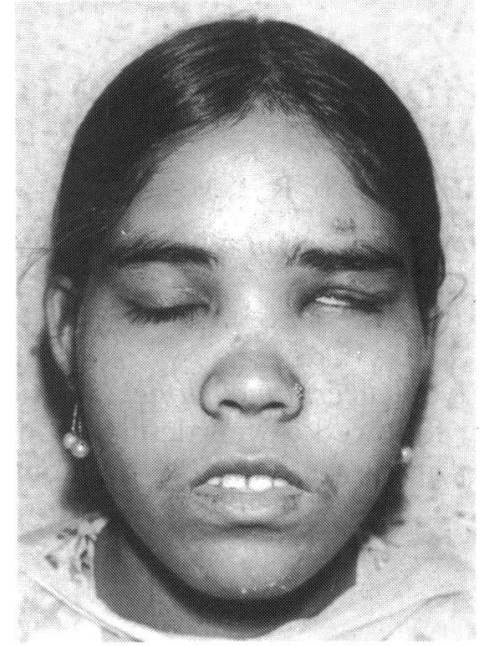

Fig. 16
Fig. 15 Late postoperative photograph showing good symmetry of lids with good lid fold and absence of Marcus Gunn phenomenon.

\section{Fig. 16 Postoperative photograph} showing lid lag.
3 Putterman AM. Jaw winking blepharoptosis treated by the Fasanella Servat procedure. Am J Ophthalmol 1973; 75: 1016-22.

4 Singh D, Singh $M$. Total transplantation of superior rectus muscle for ptosis. Trans Ophthalmol Soc UK 1978; 98: 71-4.

5 Beard C. A new treatment for severe unilateral congenital ptosis and for ptosis with jaw winking. Am J Ophthalmol 1965; 59: 252-8.

6 Callahan A. Correction of unilateral blepharoptosis with bilateral eye lid suspension. Am J Ophthalmol 1972; 74: 321-6.

7 Lemagne JM, Bemcher JM, Michiels J. Clinical, biochemical and histological results of a levator transposition for ptosis in cynomolgus monkeys. Orbit 1985; 4: 141 .
8 Lemagne JM, Bemcher JM. La transposition frontale du muscle releveur. Résultats experimentaux et application au treitement du ptosis avec synciriesic du Marcus Gunn. Acta Neurol Belg 1985; 85: 190.

9 Neuhaus RW. Eyelid suspension with a transposed levator palpebrae superioris muscle. Am J Ophthalmol 1985; 100: 308-11.

10 Betharia SM. Frontalis sling-a modified simple technique. Br J Ophthalmol 1985; 69: 443-5.

11 Illif $C$. The optimum time for surgery in the Marcus Gunn phenomenon. Ophthalmology 1970; 74: 1005-10.

Accepted for publication 16 September 1986. 